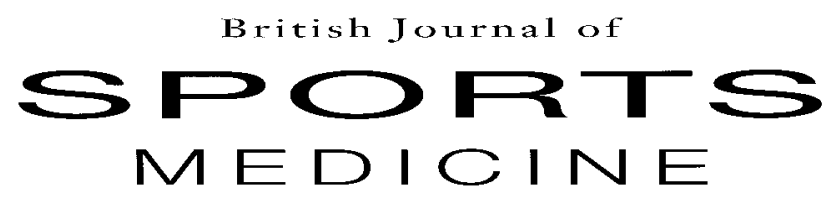

\title{
Editorials
}

\section{Warm up}

Women only. This was to be an issue devoted to women in sport, with our leaders and review articles written by women and focusing on issues of particular importance to women. It was not that simple. Battle lines are no longer drawn rigidly across sport and exercise medicine and some of our authors were ambivalent. There may be some issues about which women researchers have greater understanding but, for the most part, women authors wished to be recognised as experts in their field, irrespective of sex. Our intention was to address a perceived imbalance. Women researchers do not, however, wish to be treated as special, but as equal.

We publish leaders from all parts of the country and from every discipline. Clearly, there are issues of particular importance to women, such as dysmenorrhoea (p227) and bone health (p228), but thermoregulation is one that may not come immediately to mind (p225). Lindy Castell takes a common sense approach to dietary supplements (p226) and, despite editorial efforts for segregation of the sexes, Celia Brackenridge and Rod Jaques (p229) work together on a fascinating article on child abuse. The oral contracep- tive pill revolutionised women's lives and our review article considers its impact on sporting performance (p231). In other parts of the journal Charlotte Cowie storms that last bastion of masculinity - football (p285) and Cathy Zanker writes a spirited letter asking, "Can we really blame men for so many of the world's problems?"(p289).

Our original papers include a cardiac assessment of highly motivated fit and active veteran athletes (p239). Most people in the general population are inactive, however, and we are always searching for the ideal tool in assessment of activity. The Scottish physical activity questionnaire adds another instrument of measurement to our portfolio (p244). We learn a little more about muscle physiology in the healthy (p250) and the injured (p255) and of the effect of stretching (p259). But, sport is also about extremes and what could be more extreme than a 1600 kilometre ultramarathon (p264) or formula 1 motor racing (p270). Oh, and if all this sport is too exhausting you could consider a sabbatical. A holiday in the Antarctic, perhaps (p286).

\section{Sugar and spice, and testosterone}

Girl power! Nature or nurture, training or programming. It is a brave man who even tries to address the complicated relation between sex and sport. I may have made enemies already just by using the word "man" in our politically correct world. Mentioning sex can cause waves of indignation. But, there is no escaping the $\mathrm{Y}$ chromosome and even radical feminists can see how sport highlights differences in the species.

Competitive sport evolved in the mid-Victorian era when men were men and women stayed at home. Sport was designed for men, and the nature of most sports reflects predominantly male traits of strength, size, and shape. Indeed, many sports evolved from the celebration of the physical attributes of the successful soldier in battle. But, while the world has changed, sport has remained in times past and although we see increasing opportunities for women in sport, these simply reflect extensions of male sport rather than the introduction of sport to which women would be particularly suited. The rules, regulations, and values of sport thus remain rooted in a different era and can cause conflict between our idealised female role model and the demands of top sport.
This idealised role model also causes controversy. Different societies idealise a different female form. Traditional farming people may have different expectations of their women folk than Western world sedentary communities. No one would deny the rights of women to compete in any sport, but the nature of most sport favours male characteristics. Successful women distance runners tend to have narrow hips and a lesser q angle. Female power athletes strive for male pattern musculature. Performance is improved in most sports by the use of anabolic steroids - modifications of the male hormone testosterone. There is a clear conflict in that while we applaud the performance of top class women athletes, we in the Western world, expect women to conform to a particular image.

Our images are often defined by sexuality. Sex and sexuality are intertwined and in the past one defined the other. In the Victorian era overt homosexuality and lesbianism would not have been tolerated but we now have the Gay games. Sexuality, most certainly no longer defines sex and indeed sport may exaggerate the divergence between sexuality and sex as some sports attract the artistic man whereas others favour the strong muscular woman. 
Sport and sports administrators are used to straightforward principles that winners are first, results are the arbiter, and categories are determined by a test. The irony is that, although women may now compete with men in many sports, we must seek means to prevent men competing in women only sports. Now that athletes can have sex change operations and take appropriate hormones, sporting organisations have the difficulty of deciding who should compete in single sex category sports. This is not an easy decision and they must now arbitrate on complex issues of sex. Testing for sex is fraught with difficulty and we have seen the test change from a visual inspection to a clinical examination, and from identifying
Barr bodies to formal chromosome analysis. We still have not found the solution. We may begin to wonder if a chromosome or outward appearance should define sporting category. If a man takes female hormones and has surgery to change his sexual characteristics is (s)he male or female? Similarly, if a woman takes male sex hormones, which change her body shape, how do we define his/her sex? Is sex really an issue of body or mind? What if a man feels he is from Venus and a woman from Mars? It all used to be so simple. Rats and snails and puppy dogs tails-the $\mathrm{Y}$ chromosome.

\section{British Association of Sport and Medicine in association with the National Sports Medicine Institute}

\section{Education programme 1999}

All courses consider aspects of sports medicine other than injury. The number of delegates on these courses is limited.

General Sports Medicine Course

19-24 September

Lilleshall Hall National Sports Centre, Shrophsire (residential)

\section{Practical Sport and Medicine Course}

Club La Santa, Lanzarote (residential)

7-14 October

BASM National Congress: (Northern)

21-24 October

Gosforth Park Hotel, Newcastle

Advanced Sports Medicine Course (new)

Lilleshall Hall National Sports Centre, Shropshire (residential)

24-29 October

PGEA and CME will be sought

Intermediate Sports Injury Course-Part 1

21-26 November

Lilleshall Hall National Sports Centre, Shropshire (residential)

\section{Education programme 2000}

General Sports Medicine Course

Lilleshall Hall National Sports Centre, Shropshire (residential)

Intermediate Sports Injury Course-Part 1

Lilleshall Hall National Sports Centre, Shropshire (residential)

\section{General Sports Medicine Course}

Lilleshall Hall National Sports Centre, Shropshire (residential)

9-14 April

9-14 July

24-29 September

For further details of these courses please contact Mr Barry Hill, The National Sports Medicine Institute, c/o Medical College of St Bartholomew's Hospital, Charterhouse Square, London EC1M 6BQ.

Tel 01712510583 (ext 237). Fax 0171251 0774. Email: barry.hill@nsmi.org.uk Web site: www.nsmi.org.uk 